\title{
Second Derivative Spectrophotometric Determination of Phenytoin in Pharmaceutical Preparations
}

\author{
Yehya K. Al-Bayati and Raad R. Karabat \\ Department of Chemistry, College of Science, Baghdad University, Al-Jaderia, Baghdad-Iraq.
}

\begin{abstract}
A simple, rapid, accurate, precise, specific and economical spectrophotometric method was used for determination of phenytoin .In this study, a second derivative spectrophotometric method was used for the determination of phenytoin (PHT). This method obeys Beer's law in the employed concentration ranges of 2-10 ppm for phenytoin. The UV derivative spectra ${ }^{1} \mathrm{D}$ for (PHT) have (V) at $233.3 \mathrm{~nm},{ }^{2} \mathrm{D}$ spectra for (PHT) have (P) at $226.7 \mathrm{~nm},{ }^{3} \mathrm{D}$ spectra for PHT) have (P) at $223.6 \mathrm{~nm}$, and (V) at $230.4 \mathrm{~nm}^{4} \mathrm{D}$ spectra for (PHT) have (P) at $236.5 \mathrm{~nm}$, and (V) at 228.5nm.thelinear concentration ranges (2-10) ppm with correlation coefficient (r) 0.9996, 0.9987, 0.9973, 0.9979 . The second derivative $\mathrm{D}^{2}$ tech. at (226.7) nm successfully applied for determination the Phenytoin drug in pharmaceutical samples. Results of analysis were validated statistically and by recovery studies.
\end{abstract}

Keywords: Derivative spectroscopy, Phenytoin, Pharmaceutical analysis.

\section{Introduction}

Derivative spectrophotometry (DS) is one of the advanced modern spectrophotometric techniques It is based on so called derivative spectra [1] which are generated from parent zero order ones. The derivatization [2] of zeroorder spectrum can lead to separation of overlapped signals, elimination of background caused by presence of other compounds in a sample. Derivative spectrophotometry involves the conversion of normal spectrum (fundamental, zeroth order spectrum) to its first, second or higher derivative spectrum by differentiating absorbance (dA) of sample with respect to "wavelength $(\mathrm{d} \lambda)$ or time $(\mathrm{dt})$ " versus wavelength $(\lambda)$ or time $(t)[3]$. This technique becomes very useful, additional tool which helps to resolve various analytical problems. It has found application in many fields of analysis, especially in pharmaceutical, clinical and biochemical as well as in inorganic or organic analysis. Derivative spectra can be obtained by optical, electronic or mathematical methods [4,5]. Phenytoin has the molecular formula $\mathrm{C}_{15} \mathrm{H}_{12} \mathrm{~N}_{2} \mathrm{O}_{2}$ and the chemical name 5,5diphenylimidazolidine-2,4-dione with molecular weight of (252.268) $\mathrm{gm} \mathrm{mol}^{-1}$. Phenytoin is an anticonvulsant drug, which is useful in the treatment of epilepsy. The primary site of action appears to be the motor cortex where spread of seizure activity is inhibited [6]. Phenytoin is also used to control arrhythmias (irregular heartbeat) and to treat migraine headaches and facial nerve pain. Phenytoin (diphenylhydantoin) was first synthesized by German physician Heinrich Biltz in 1908. In 1938, outside scientists including. Phenytoin is one of the most widely used drug in the therapy of epilepsy. However, its low solubility in water, both as free acid and sodium salt, makes its administration to patients difficult and seldom satisfactory. Phenytoin is given orally as sodium salt in a strong alkaline solution, since it requires a $\mathrm{pH}$ between 10 and 12 to be maintained in solution [7]. Other methods for the estimation of phentoin in pharmaceutical preparation andor biological fluid [8], spectrophotometry using Orthogonal function [9], thin layer chromatography [10], and high performance liquid chromatography (HPLC) [11]. In these wark using spectrophotometric method for determination of (PHT) by derivative spectrophotometric technique [12].

\section{Experimental}

\section{Materials and Reagents}

1-Standard antibiotic drugs: Phenytoin $\left(\mathrm{C}_{15} \mathrm{H}_{12} \mathrm{~N}_{2} \mathrm{O}_{2}\right.$ F.W. 252.268), were gift from the State Company of Drug Industries and Medical Appliances (IRAQ-SDI- Samara). 2-Phenergan tablets (100 mg Phenytion Sodium) (Park-Davis Company, Germany, and Pfizer Company, turkey) were purchased locally. 


\section{Apparatus}

1-Doublebeam

UV-Visible

spectrophotometer model (UV-1650 PC) SHIMADZ (Japan), interfaced with computer via a SHIMADZU UV probe data system program (Version 1.10 ), using $1.00 \mathrm{~cm}$ quartz cells.

\section{Standard Solutions for DS Studies}

We used pestle and mortar to grind the tablets to a fine powder. Amounts equivalent to one tablet were weighed and taken into $100 \mathrm{~mL}$ volumetric flasks. Samples were mixed by magnetic stirrers for $45 \mathrm{~min}$. and filtered through 0.45 um cellulose filter paper. Standard solution of (100 ppm) Phenytoin was prepared by dissolving $0.0100 \mathrm{gm}$ in a small amount of deionized distilled water and then diluted to $100 \mathrm{ml}$ with deionized distilled water. More diluted solution was prepared by subsequent dilution of the stock solutions to (2,4,6,8 and 10) ppm Phenytoin solution.

\section{LOD and LOQ}

Limit of detection (LOD) and limit of quantitation (LOQ) values calculated according to ICH Guideline [13]:

$\mathrm{LOD}=3 \mathrm{SD} / \mathrm{m} \mathrm{LOQ}=10 \mathrm{SD} / \mathrm{m}$ where $\mathrm{SD}$ is the standart deviation of intercept and $\mathrm{m}$ is the slope of calibration curve.

\section{Preparation of pharmaceutical samples}

Two types of capsules were used to determine the concentration of Phenytoin:

1. Germany: (100 mg Phenytion Sodium), one pill of this capsule was grinded and dissolved in deionized distilled water and completed in volumetric flask to $(100 \mathrm{ml})$.

2. Turkey: (100 mg Phenytion Sodium), one pill of this capsule was grinded and dissolved in deionized distilled water and completed in volumetric flask to $(100 \mathrm{ml})$.

A total of 20 tablets of Phenytoin were opened and the contents were weighed and mixed. Accurately weighed and powdered. An aliquot of powder equivalent to the weight of 1 tablet was accurately weighed and transferred to volumetric flask and was dissolved in $100 \mathrm{ml}$ of deionized distilled water with stirred for about $45 \mathrm{~min}$ and then volume made up with deionize distilled water. This solution was filtered to remove any insoluble matter. The filtrate was collected in a clean flask. Appropriate dilutions were made to obtain $10 \mathrm{mg} / \mathrm{L}$ with water from stock solution for both UV and derivative spectrophotometric method.

\section{Results and Discussion}

Normal UV spectrums of PHT has one absorption maximum wavelengths at $288.0 \mathrm{~nm}$ with concentration range $2-10 \mathrm{mg} / \mathrm{L}$, as shown in Fig. (7).

\section{Derivative Spectrophotometry}

The UV derivative spectra ${ }^{1} \mathrm{D},{ }^{2} \mathrm{D},{ }^{3} \mathrm{D}$ and ${ }^{4} \mathrm{D}$ have derived from normal spectrum of PHT as Shawn in Fig. (7).

\section{1- First Derivative}

${ }^{1} \mathrm{D}$ spectra for PHT have derived from normal spectra using $(S=10)$, with $(\Delta \lambda=2)$. Fig.(7) shows that ${ }^{1} \mathrm{D}$ spectra have $\mathrm{V}$ at $233.3 \mathrm{~nm}$. Calibration curves were constructed for the wavelengths $233.3 \mathrm{~nm}$, as shown in Fig.(1). The linear dynamic ranges, the linear equations and correlation coefficients of the calibration curves are listed in Table (1).

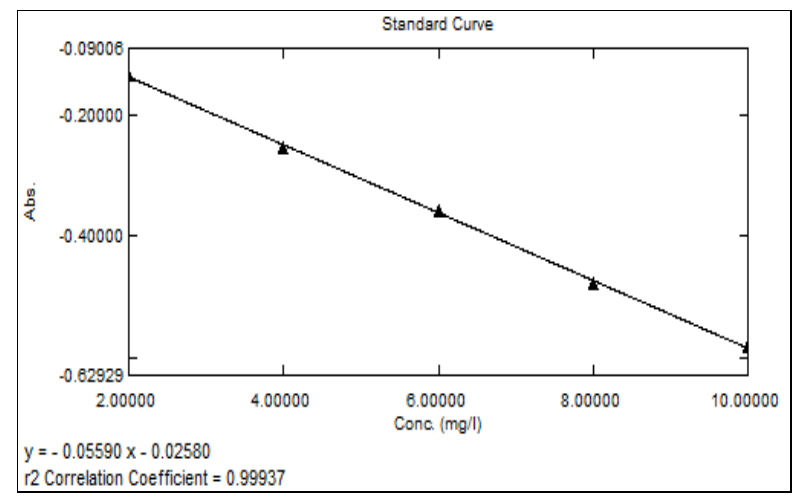

Fig.(1): Calibration curve of ${ }^{1} D$ spectra for PHT (2-10) ppm at $V=233.3 n m$.

\section{2- Second Derivative}

${ }^{2} \mathrm{D}$ spectra of PHT have derived for normal spectra using $(\mathrm{S}=30)$, with $(\Delta \lambda=4)$, as shown in Fig.(7). ${ }^{2} \mathrm{D}$ spectra show peak (P) at $226.7 \mathrm{~nm}$, Calibration curve was constructed at wavelengths $226.7 \mathrm{~nm}$, as shown in Fig.(2). The linear equation, correlation coefficients and the concentration ranges for the calibration curves are listed in Table (1). 


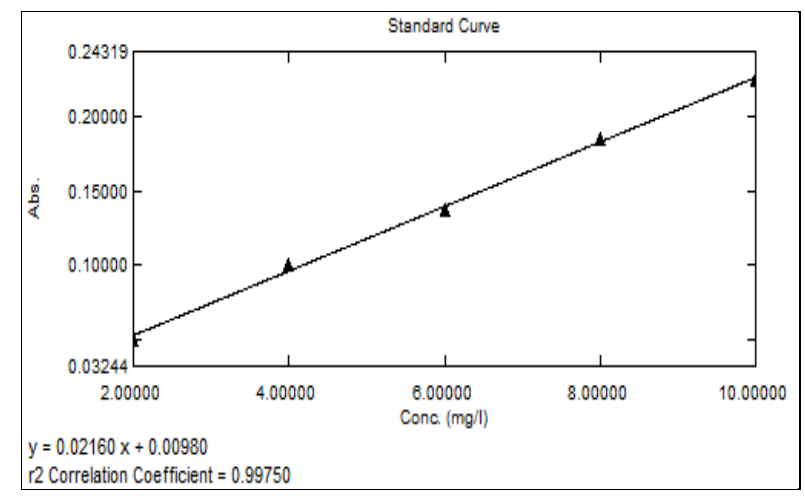

Fig.(2): Calibration curve of ${ }^{2} D$ spectra for PHT 2-10 ppm at $P=226.7 \mathrm{~nm}$.

\section{3- Third Derivative}

${ }^{3} \mathrm{D}$ spectra for PHT have derived from normal spectra using $(S=40)$, with $(\Delta \lambda=8)$. Fig. (7) shows that ${ }^{3} \mathrm{D}$ spectra have $\mathrm{P}$ at $223.6 \mathrm{~nm}$, and $\mathrm{V}$ at $230.4 \mathrm{~nm}$. Calibration curves were constructed at 223.6 and $230.4 \mathrm{~nm}$, as shown in Fig.(3) and (4) respectively. The linear equations, correlation coefficients and the concentration ranges for the calibration curves are listed in table (3.30).

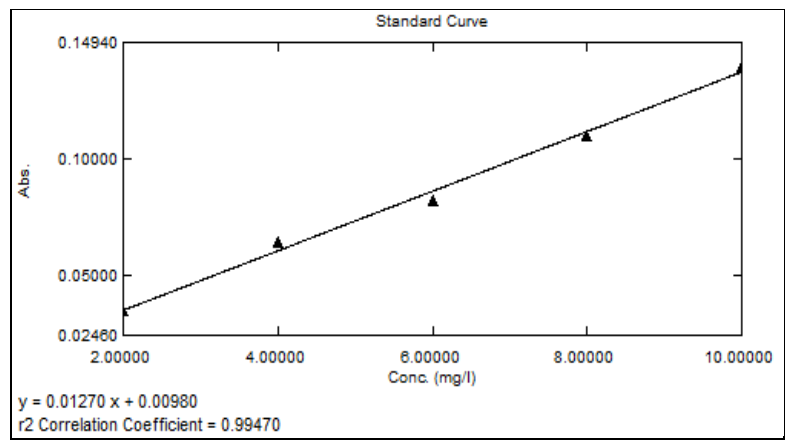

Fig.(3): Calibration curve of ${ }^{3} D$ spectra for PHT 2-10 ppm at $P=223.6 \mathrm{~nm}$.

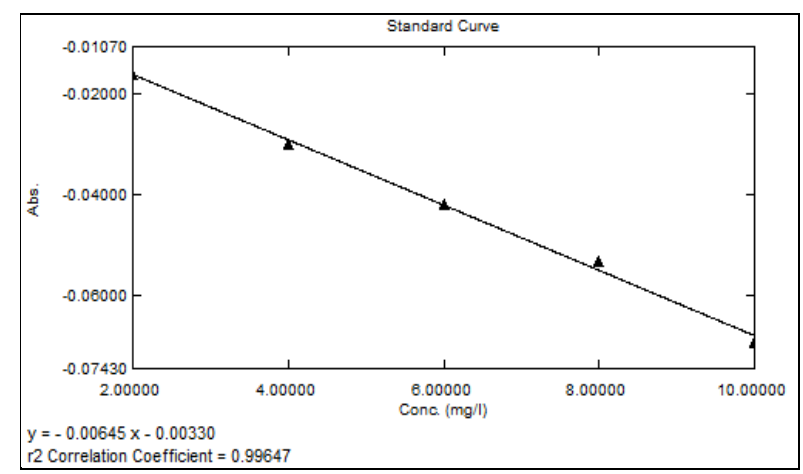

Fig.(4): Calibration curve of ${ }^{3} D$ spectra for PHT 2-10 ppm at $V=230.4 \mathrm{~nm}$.

\section{4- Fourth Derivative:}

${ }^{4} \mathrm{D}$ spectra for PHT have derived from normal spectra using $(\mathrm{S}=160)$, with $(\Delta \lambda=16)$. Fig.(7) shows ${ }^{4} \mathrm{D}$ spectra with $\mathrm{P}$ at $236.5 \mathrm{~nm}$, and $\mathrm{V}$ at $228.5 \mathrm{~nm}$. Calibration curves were constructed for the wavelengths 236.5 and $228.5 \mathrm{~nm}$, as shown in Fig.(5) and (6) respectively. The linear equations, correlation coefficients and the concentration ranges for the calibration curves are listed in Table (1).

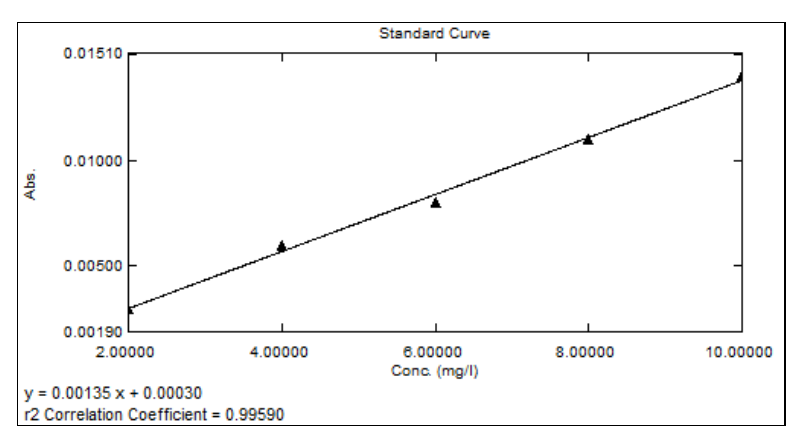

Fig.(5): Calibration curve of ${ }^{4} D$ spectra for PHT2-10 ppm at $P=236.5 \mathrm{~nm}$.

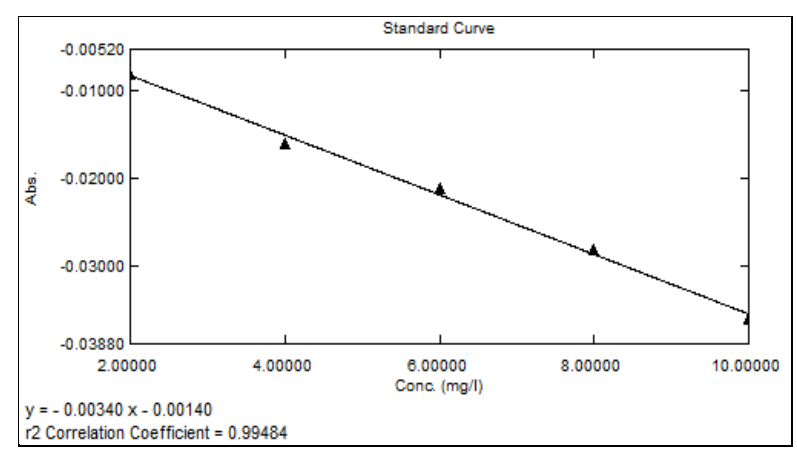

Fig. (6): Calibration curve of ${ }^{4} D$ spectra for PHT 2-10 ppm at $V=228.5 \mathrm{~nm}$. 


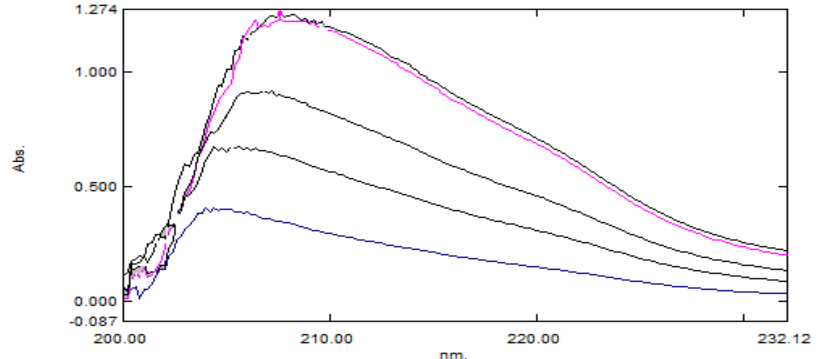

(a)

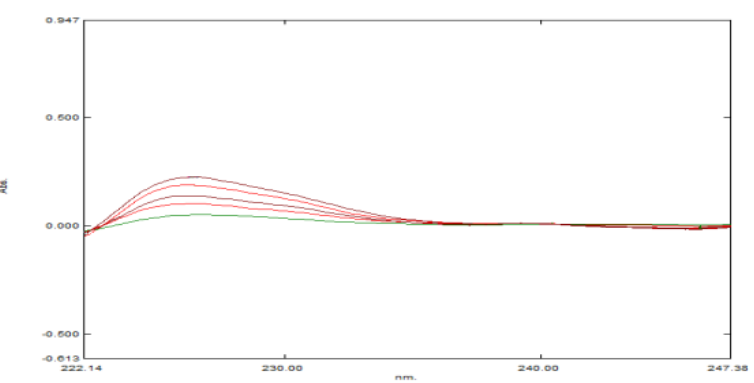

(c)

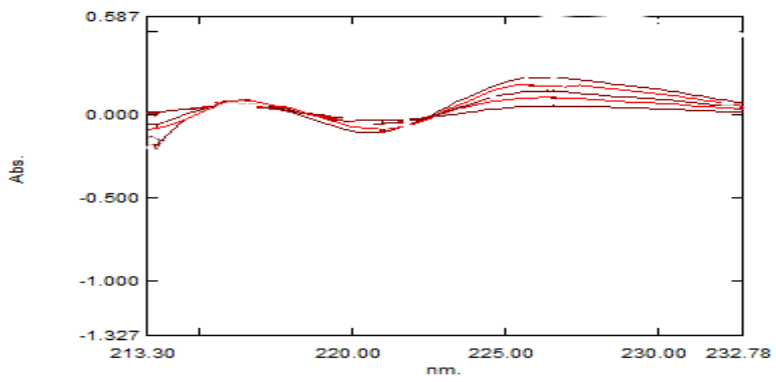

(b)

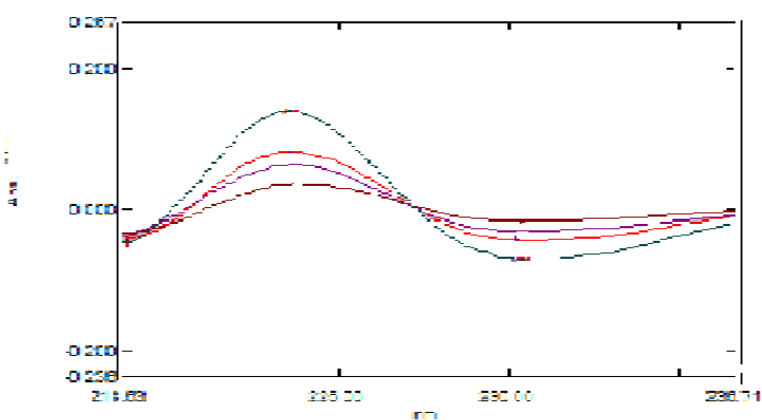

(d)

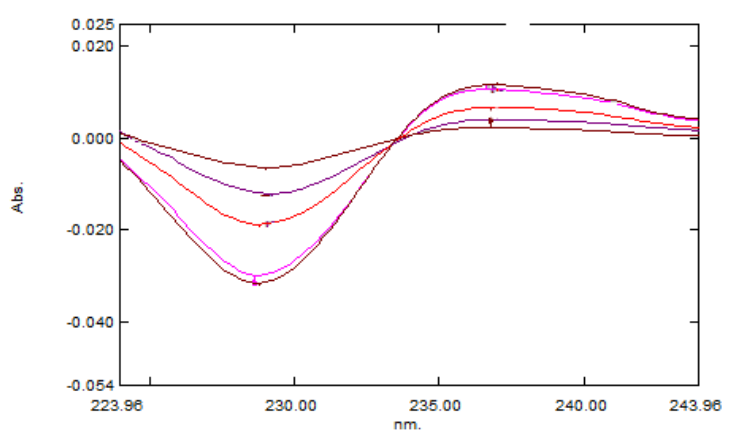

(e)

Fig.(7): Spectra of 2-10 ppm PHT, a- Normal spectra

$b$ - First derivative spectra $(S=10, \lambda=2)$

c-Second derivative spectra $(S=30, \lambda=4)$

$d$ - Third derivative spectra $(S=40, \lambda=8)$

$e$ - Fourth derivative spectra $(S=160, \lambda=16)$.

Table (1)

The parameters obtained from the calibration curves for DS tech. of PHT.

\begin{tabular}{|c|c|c|c|c|c|c|c|}
\hline Tech. & $\begin{array}{c}\text { Conc.r } \\
\text { ange } \\
\text { mg/L } \\
\end{array}$ & $\Lambda(n m)$ & Equation & $r$ & $\begin{array}{c}\text { Linearity } \\
\text { range } \\
(\mathrm{mg} / \mathrm{L}) \\
\end{array}$ & $\begin{array}{c}* L O \\
Q \\
m g / L\end{array}$ & $\begin{array}{c}{ }^{*} L O D \\
m g / L\end{array}$ \\
\hline${ }^{1} \mathbf{D}$ & $2-10$ & $V=233.3$ & $Y=-0.05590 x-0.02580$ & 0.9996 & $(2-10)$ & 0.288 & 0.193 \\
\hline \multirow{2}{*}{${ }^{2} \mathbf{D}$} & $2-10$ & $\mathrm{P}=226.8$ & $\bar{~} \mathrm{Y}=0.02160 \mathrm{x}+0.00980$ & 0.9987 & $(2-10)$ & 0.386 & 0.190 \\
\hline & $2-10$ & $\mathrm{~V}=221.0$ & $\bar{P}=-0.00965 x+0.00290$ & 0.9985 & $(2-10)$ & 0.245 & 0.133 \\
\hline \multirow{2}{*}{${ }^{3} \mathbf{D}$} & $2-10$ & $\mathrm{P}=223.6$ & $\mathrm{Y}=0.01270 \mathrm{x}+0.00980$ & 0.9973 & $(2-10)$ & 0.184 & 0.170 \\
\hline & $2-10$ & $\mathrm{~V}=230.4$ & $Y=-0.00645 x-0.00330$ & 0.9973 & $(2-10)$ & 0.243 & 0.225 \\
\hline \multirow{2}{*}{${ }^{4} \mathbf{D}$} & $2-10$ & $\mathrm{P}=236.5$ & $\bar{P} \mathrm{Y}=0.00135 \mathrm{x}+0.00030$ & 0.9979 & $(2-10)$ & 1.207 & 0.857 \\
\hline & $2-10$ & $\mathrm{~V}=228.5$ & $\bar{~} \mathrm{Y}=-0.00340 \mathrm{x}-0.00140$ & 0.9974 & $(2-10)$ & 1.088 & 0.196 \\
\hline
\end{tabular}

$* L O D=3 S D_{B} / m, L O Q=10 S D_{B} / m ;$ where $S D_{B}=$ standard deviation of blank; $m=$ slope [14]. 
Phenytoin can be determined using the above tech. The results for determination standard samples of PHT (2,4,6,8 and 10ppm) and the relative errors are listed in Table (2).

Table (2)

The relative error and recovery for the determination standard sample of (2-10) ppm PHT by using DS tech.

\begin{tabular}{|c|c|c|c|c|c|c|}
\hline Phenytoin & Concentration & $2 p p m$ & 4ppm & 6ppm & 8ppm & 10ppm \\
\hline \multirow{4}{*}{$\begin{array}{c}{ }^{1} D \\
V= \\
\mathbf{2 2 3 . 3}\end{array}$} & Found mg/L & 1.922 & 4.238 & 5.733 & 8.129 & 9.976 \\
\hline & RE\% & -3.90 & $\begin{array}{c}5.97 \\
\end{array}$ & $\begin{array}{l}-4.45 \\
\end{array}$ & 1.26 & $\begin{array}{c}-0.24 \\
\end{array}$ \\
\hline & RC\% & 96.16 & 105.97 & 95.55 & 101.62 & 99.76 \\
\hline & RSD\% & 1.44 & 3.31 & 2.89 & 1.09 & 0.59 \\
\hline \multirow{4}{*}{$\begin{array}{c}{ }^{2} D \\
P=226.7\end{array}$} & Found $\mathrm{mg} / \mathrm{L}$ & 2.029 & 4.038 & 5.786 & 8.196 & 9.949 \\
\hline & RE\% & 1.46 & 0.95 & -3.57 & 2.46 & $\begin{array}{l}-0.50 \\
\end{array}$ \\
\hline & $\overline{\mathrm{RC} \%}$ & 101.46 & 100.95 & 96.43 & 102.46 & 999.50 \\
\hline & RSD\% & 8.57 & 4.58 & 2.59 & 4.24 & 2.21 \\
\hline \multirow{4}{*}{$\begin{array}{c}{ }^{3} D \\
P=223.6\end{array}$} & Found $\mathrm{mg} / \mathrm{L}$ & 1.930 & 4.119 & 5.712 & 8.494 & 9.743 \\
\hline & RE\% & -3.46 & 2.98 & -4.79 & 6.18 & -2.57 \\
\hline & RC\% & 96.54 & 102.98 & 95.21 & 106.18 & 97.43 \\
\hline & RSD\% & 8.46 & 4.96 & 1.65 & 6.17 & 3.87 \\
\hline \multirow{4}{*}{$\begin{array}{c}{ }^{3} \mathrm{D} \\
\mathrm{V}=\mathbf{2 3 0 . 4}\end{array}$} & Found $\mathrm{mg} / \mathrm{L}$ & 2.029 & 4.038 & 5.786 & 8.196 & 9.949 \\
\hline & RE\% & 1.46 & 0.95 & -3.57 & 2.46 & -0.50 \\
\hline & RC\% & 101.46 & 100.95 & 96.43 & 102.46 & 999.50 \\
\hline & RSD\% & 6.96 & 4.16 & 3.11 & 5.82 & 2.63 \\
\hline \multirow{4}{*}{$\begin{array}{c}{ }^{4} D \\
P=236.5\end{array}$} & Found $\mathrm{mg} / \mathrm{L}$ & 1.996 & 4.03 & 5.798 & 8.326 & 9.847 \\
\hline & RE\% & -0.20 & 0.77 & -3.36 & 4.09 & -1.52 \\
\hline & RC\% & 99.80 & 100.77 & 96.64 & 104.09 & 98.48 \\
\hline & RSD\% & 7.72 & 8.61 & 1.42 & 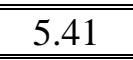 & 3.01 \\
\hline \multirow{4}{*}{$\begin{array}{c}{ }^{4} D \\
V=228.5\end{array}$} & Found mg/L & 1.941 & 4.098 & 5.764 & 8.411 & 9.784 \\
\hline & RE\% & -2.94 & 2.45 & -3.92 & 5.15 & -2.16 \\
\hline & RC\% & 97.06 & 102.45 & 96.08 & 105.15 & 97.84 \\
\hline & RSD\% & 3.03 & 7.08 & 1.02 & 7.36 & 4.22 \\
\hline
\end{tabular}

\section{Analysis of Pharmaceutical Samples}

\section{1- Application to pharmaceutical samples}

The method described by the author is successfully applied on the pharmaceutical compounds containing phenytoin. The RE\%, $\mathrm{RC} \%$ and $\mathrm{RSD} \%$ are calculated in each case and are From the above parameters Table (2) it seems that the signal measurement using second derivative would give better results when compared with other derivatives. The suitable teach. was the ${ }^{2} \mathrm{D}$ at $226.7 \mathrm{~nm}$. Germany and Turkey samples $(6 \mathrm{mg} / \mathrm{L})$ were measured by using this tech. and compared with standard as shown in Table (3). 
Table (3)

Statistical data for the determination of (PHT) in pure and pharmaceutical form by ${ }^{2} \mathrm{D}$ tech.

\begin{tabular}{|c|c|c|c||}
\hline Drugs & Standard & Epanutin(Germany) & Epanutin(Turkey) \\
\hline \hline *Found(ppm) & 5.786 & 6.233 & 5.755 \\
\hline $\mathbf{R E \%}$ & -3.57 & 3.88 & -4.08 \\
\hline $\mathbf{R C \%}$ & 96.43 & 103.88 & 95.92 \\
\hline $\boldsymbol{\mu}=\overline{\mathbf{x}} \pm(\mathbf{t} \boldsymbol{\delta}) / \sqrt{\mathbf{n}}$ & $5.786 \pm 0.374$ & $6.233 \pm 0$. & $5.755 \pm 0$. \\
\hline $\mathbf{\Delta} \mathbf{- 1}$ & 0.150 & 0.141 & 0.082 \\
\hline $\mathbf{R S D} \%$ & 2.598 & 3.315 & 1.651 \\
\hline F experimental & 2.818 & 3.263 & 10.333 \\
\hline F theoretical & \multicolumn{3}{|l}{19.0} \\
\hline
\end{tabular}

* Each measurement was repeated three times.

Comparison between Derivative Spectrophotometry (DS) and ion selective electrode (ISEs) Methods

Methods for phenytoin determination was compared using $\mathrm{F}$ test, in order to compare between the proposed methods with respect to ion selective electrode (ISEs) method. These methods are rapid, simple and accurate, to compare between them, (2.5) ppm phenytoin was determined by ISEs using PHTNaT+DBPH electrode (direct method) $(n=3)$, and by DS method using ${ }^{2} \mathrm{D}$ at $(226.7) \mathrm{nm}$

Table (4)

The parameters of ISE and DS methods to determine Phenytoin (ppm).

\begin{tabular}{|c|c|c|}
\hline Parameter & ISEs using PHT-NaT+DBPH & DS using $D^{1}$ at $267 \mathrm{~nm}$ \\
\hline Linear range & $\begin{array}{c}5 \times 10^{-5}-1 \times 10^{-2} \mathrm{M} \\
(21-420 \mathrm{ppm})\end{array}$ & $\begin{array}{c}4 \times 10^{-6}-2 \times 10^{-2} \mathrm{M} \\
(2-100 \mathrm{ppm})\end{array}$ \\
\hline Detection limit & $6 \times 10^{-6} \mathrm{M}(1.513 \mathrm{ppm})$ & $7 \times 10^{-6} \mathrm{M}(2 \mathrm{ppm})$ \\
\hline Standard deviation & 0.478 & 0.166 \\
\hline RSD\% & 0.302 & 2.698 \\
\hline $\mathrm{S}^{2}$ & 0.028 & 0.027 \\
\hline PHT. found $\mathrm{mg} / \mathrm{L}$ & $1.025 \times 10^{-5}$ & 2.588 \\
\hline RE\% & 2.50 & 3.52 \\
\hline Recovery \% & 102.50 & 103.52 \\
\hline F experimental & \multicolumn{2}{|c|}{8.444} \\
\hline F theoretical & \multicolumn{2}{|l|}{19.0} \\
\hline
\end{tabular}

The results of the DS Phenytoin proposed method was compared successfully with the results of the British Pharmacopoeia standard method using F-test. Where $\mathrm{F}=\mathrm{S}_{1}^{2} / \mathrm{S}^{2}, \mathrm{~S}_{1}^{2}>$ $\mathrm{S}^{2}$ from the results in table (4) by comparing the F-calculated value from the experiment with the F-value from the table with confidence limit of $95 \%$, the results indicate $(\mathrm{n}=3)$. The values of $\mathrm{F}$ at $95 \%$ confidence level is 19.00 standard deviation (s) were 0.478 and 0.166 for ISEs and DS methods, respectively. Therefore the resulting $\mathrm{F}$ is equal to 8.444 . The results obtained by ISEs were quite comparable with DS method. Other parameters for the methods are listed in Table (4). that there is no significant difference between the precisions of two methods.

\section{References}

[1] Talsky G., "Derivative Spectrophotometry, firsted, VCH, Weinheim", (1994).

[2] Savitzky A., Golay M.J.E., "Smoothing and differentiation of data by simplified 
least squares procedures" Anal. Chem., 36 (8), 1627-1642, 1964.

[3] Beckett A.H. and Stenlake J.B. Practical Pharmaceuticalchemistry. $4^{\text {th }}$ ed.part2, New Delhi: CBS publishers and Distributors. 2002.

[4] Nowicka-Jankowska T., Wieteska E., Gorczynska K., Michalik A., "UV-Vis spectrophotometry in chemical analysis, first ed"., Elsevier, Netherlands, (1986).

[5] Görög S., "Ultraviolet-Visible Spectrophotometryin Pharmaceutical Analysis, first ed". CRC Press, Boca Ralton, (1995).

[6] Cattral, R. W., Chemical Sensors, Oxford Science Publications, Series Sponser ZENECA (1997).

[7] Bosch J, Roca T, Domenech J, Suriol M. "Synthesis of water-soiuble Phenytoinprodrugs", Bioorg, Med. chem Leff, 9,(2),1859-1862,1999.

[8] Buck R. P., Lindner E., "Tracing the History of Selective Ion Sensors" Anal. Chem., 73(3), 88-97, 2001.

[9] Zareba S., Szarwilo K., Pomykalski A., "Determination of $\mathrm{Fe}(\mathrm{II})$ and $\mathrm{Zn}$ (II) by spectrophotometry, atomic absorption spectrometry and ions chromatographymethodsin Vitrum", Farmaco, 60(7), 459-64, 2005.

[10] Basu M., Sarkar S., Pande S., Jana S., Sinha A. K., S. Sarkar S., Pradhan M., Pal A., Pal T. "Fabrication and use of new solid state phosphateion selective electrode for monitoring phosphorylation and dephosphorylation reactions", Chem. Commun, 3(6),7191-7193,(2009).

[11] Ekemekci G., Kalayci S., Somer G., "A solid state hydroxide ion selective electrode for the measurement of high $\mathrm{pH}$ values". Sensor Actuator, 10,(2) ,PP 260-264, 2004.

[12] El-Sayed, A-A. and El-Salem, N.A, "Recent Development of Derivatives Spectrophotometry and Their Analytical Application" Anal. Sci, 21,( 5), 595-614, 2005.

[13] ICH Harmonized Tripartite Guideline, International Conference on Harmonization of Technical Requirements for Registration of Pharmaceuticals for Human Use, Validation of Analytical Procedure: Methodology (1996) International
Conference on Harmonization, Geneva, Switzerland.

[14] British Pharmacopoeia, "Medicinal and pharmaceutical Substances", published by (MHRA), 1(3),.31-5, 31-6, 2009. 